\title{
Addition of zoledronic acid to neoadjuvant chemotherapy is not beneficial in patients with HER2-negative stage II/III breast cancer: 5 -year survival analysis of the NEOZOTAC trial (BOOG 2010-01)
}

\author{
Stefanie de Groot ${ }^{1}$, Hanno Pijl2 , Ayoub Charehbili ${ }^{1,5}$, Saskia van de Ven ${ }^{3}$, Vincent T. H. B. M. Smit ${ }^{4}$,
} Elma Meershoek-Klein Kranenbarg ${ }^{5}$, Joan B. Heijns ${ }^{6}$, Laurence J. C. van Warmerdam7, Lonneke W. Kessels ${ }^{8}$, M. Wouter Dercksen ${ }^{9}$, Manon J. A. E. Pepels ${ }^{10}$, Hanneke W. M. van Laarhoven ${ }^{11}$, Birgit E. P. J. Vriens ${ }^{7}$, Hein Putter ${ }^{12}$, Marta Fiocco ${ }^{12,13}$, Gerrit-Jan Liefers ${ }^{5}$, Jacobus J. M. van der Hoeven ${ }^{1,14}$, Johan W. R. Nortier ${ }^{1}$, Judith R. Kroep ${ }^{1 *}$ and on behalf of the Dutch Breast Cancer Research Group ${ }^{15}$

\begin{abstract}
Background: Adjuvant bisphosphonates are associated with improved breast cancer survival in postmenopausal patients. Addition of zoledronic acid (ZA) to neoadjuvant chemotherapy did not improve pathological complete response in the phase III NEOZOTAC trial. Here we report the results of the secondary endpoints, disease-free survival, (DFS) and overall survival (OS).

Patients and methods: Patients with HER2-negative, stage II/III breast cancer were randomized to receive the standard 6 cycles of neoadjuvant TAC (docetaxel/doxorubicin/cyclophosphamide) chemotherapy with or without $4 \mathrm{mg}$ intravenous (IV) ZA administered within $24 \mathrm{~h}$ of chemotherapy. This was repeated every 21 days for 6 cycles. Cox regression models were used to evaluate the effect of ZA and covariates on DFS and OS. Regression models were used to examine the association between insulin, glucose, insulin growth factor-1 (IGF-1) levels, and IGF-1 receptor (IGF-1R) expression with survival outcomes.

Results: Two hundred forty-six women were eligible for inclusion. After a median follow-up of 6.4 years, OS for all patients was significantly worse for those who received ZA (HR 0.468, 95\% Cl 0.226-0.967, $P=0.040$ ). DFS was not significantly different between the treatment arms (HR 0.656, 95\% Cl 0.371-1.160, $P=0.147$ ). In a subgroup analysis of postmenopausal women, no significant difference in DFS or OS was found for those who received ZA compared with the control group (HR 0.464, 95\% Cl 0.176-1.222, $P=0.120$; HR 0.539, 95\% Cl 0.228-1.273, $P=0.159$, respectively). The subgroup analysis of premenopausal patients was not significantly different for DFS and OS ((HR 0.798, 95\% Cl 0.369$1.725, P=0.565 ;$ HR $0.456,95 \% \mathrm{Cl} 0.156-1.336, P=0.152$, respectively). Baseline IGF-1R expression was not significantly associated with DFS or OS. In a predefined additional study, lower serum levels of insulin were associated with improved DFS (HR 1.025, 95\% Cl 1.005-1.045, $P=0.014)$.

\footnotetext{
* Correspondence: j.r.kroep@lumc.nl

${ }^{1}$ Department of Medical Oncology, Leiden University Medical Center,

Albinusdreef 2, Leiden, P.O. Box 9600, 2300 RC Leiden, The Netherlands

Full list of author information is available at the end of the article
}

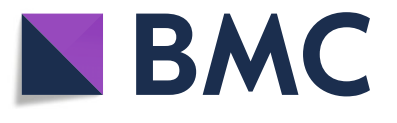

(c) The Author(s). 2019 Open Access This article is distributed under the terms of the Creative Commons Attribution 4.0 International License (http://creativecommons.org/licenses/by/4.0/), which permits unrestricted use, distribution, and reproduction in any medium, provided you give appropriate credit to the original author(s) and the source, provide a link to the Creative Commons license, and indicate if changes were made. The Creative Commons Public Domain Dedication waiver (http://creativecommons.org/publicdomain/zero/1.0/) applies to the data made available in this article, unless otherwise stated. 


\begin{abstract}
(Continued from previous page)
Conclusions: Our results suggest that ZA in combination with neoadjuvant chemotherapy was associated with a worse OS in breast cancer (both pre- and postmenopausal patients). However, in a subgroup analysis of postmenopausal patients, ZA treatment was not associated with DFS or OS. Also, DFS was not significantly different between both groups. IGF-1R expression in tumor tissue before and after neoadjuvant treatment did not predict survival.
\end{abstract}

Trial registration: ClinicalTrials.gov, NCT01099436, April 2010.

Keywords: Breast cancer, Neoadjuvant chemotherapy, Zoledronic acid, Survival, Insulin, IGF-1R

\section{Introduction}

Bisphosphonates (BPs) act to suppress bone resorption by inducing osteoclast apoptosis $[1,2]$. BPs are indicated for treatment and prevention of osteoporosis and prevention of skeletal-related events due to metastasis of solid tumors or multiple myeloma [3]. Results of the meta-analysis of the Early Breast Cancer Trialists' Collaborative Group (EBCTCG) showed that adjuvant BPs were associated with decreased fracture rate, as well as improved breast cancer survival and bone metastasis risk. These benefits were only found in postmenopausal (natural or induced) women in a subgroup analysis [4]. The benefits may be explained by the increased bone resorption in postmenopausal patients, as BP prevented tumor growth in bone in a postmenopausal model but not in a premenopausal model [5]. Currently, BPs are considered as a part of the adjuvant breast cancer treatment in postmenopausal patients and patients receiving ovarian suppression therapy [6]. The exact mechanism of the anti-tumor effect of BPs is unknown. However, the following mechanisms have been proposed [7], BPs may (1) prevent tumors cells from metastasizing to the bone by decreasing bone turnover [8], (2) change the bone micro-environment by reducing growth factors such as insulin-like growth factor-1 (IGF-1) and insulin and thereby inhibit proliferation [9-12], (3) have immunomodulatory properties by activating $\gamma \delta \mathrm{T}$ cells $[13,14]$ and recruiting tumor-associated macrophages $[15,16]$, (4) reduce angiogenic factors $[17,18]$, and/or (5) kill dormant disseminated tumor cells $[19,20]$. BP was reported to improve the tumor response when combined with doxorubicin in an experimental breast cancer model [21]. Moreover, adding a BP to neoadjuvant chemotherapy in breast cancer patients resulted in a significantly lower residual invasive tumor size and a non-significantly higher pathological complete response $(\mathrm{pCR})$ rate in an exploratory evaluation of the AZURE trial [22].

Clinically, in our phase III randomized NEOZOTAC study examining the effect of zolendronic acid (ZA) in addition to neoadjuvant TAC chemotherapy in HER2 negative early breast cancer, ZA did not improve the primary endpoint, pathological complete response (pCR) [23].
A subsequent meta-analysis did not show a significant increase in $\mathrm{PCR}$ rate when adding a BP to neoadjuvant chemotherapy in patients with early breast cancer $[16,24]$. In this paper, we report the secondary endpoints of disease-free survival (DFS) and overall survival (OS) from the NEOZOTAC study [23].

Additionally, we report associations between the IGF-1 receptor (IGF-1R) expression and the concentrations of circulating growth factors such as insulin and IGF-1, and survival. IGF-1R and insulin receptor isoform A (IRA) are frequently upregulated in breast cancer [25, 26]. Both receptors activate the Ras/mitogen-activated protein kinase (MAPK) and phosphatidylinositol-3-kinase (PI3K)/AKT pathways, through which cell proliferation is stimulated and apoptosis is inhibited [27].

\section{Methods \\ Study population}

As previously described [23], from July 2010 until April 2012, 250 women participated in the multi-center phase III NEOZOTAC trial and 246 were evaluated in the study ( 2 patients were ineligible and 2 patients withdrew informed consent; Fig. 1). Eligible patients had a histologically confirmed diagnosis of HER2 negative, stage II or III (T2 any $\mathrm{cN}, \mathrm{cM} 0$ ) early breast cancer, adequate bone marrow (i.e., white blood cell count $\geq 3.0 \times 10^{9} / \mathrm{L}$, neutrophil count $\geq 1.5 \times 10^{9} / \mathrm{l}$, and platelet count $\geq$ $100 \times 10^{9} / \mathrm{l}$ ), normal liver function (i.e., bilirubin $\leq 1.5 \times$ upper limit of normal (UNL) range, ALAT and/or ASAT $\leq 2.5 \times \mathrm{UNL}$, alkaline phosphatase $\leq 5 \times \mathrm{UNL}$ ), adequate renal function (i.e., calculated creatinine clearance $\geq 50$ $\mathrm{mL} / \mathrm{min}$ ), adequate cardiac function, WHO performance state $0-2$, age $\geq 18$ years, absence of pregnancy or current lactation, and written informed consent. Menopause was defined as 1 year without menstrual activity, previous bilateral oophorectomy, age older than 60 years or baseline FSH $>20 \mathrm{U} / \mathrm{l}$, and estradiol $<110 \mathrm{pmol} / \mathrm{l}$. The study (NCT01099436) was conducted in accordance with the Declaration of Helsinki (October 2008) and was approved by the Ethics Committee of the LUMC in agreement with the Dutch law for medical research involving human subjects. 


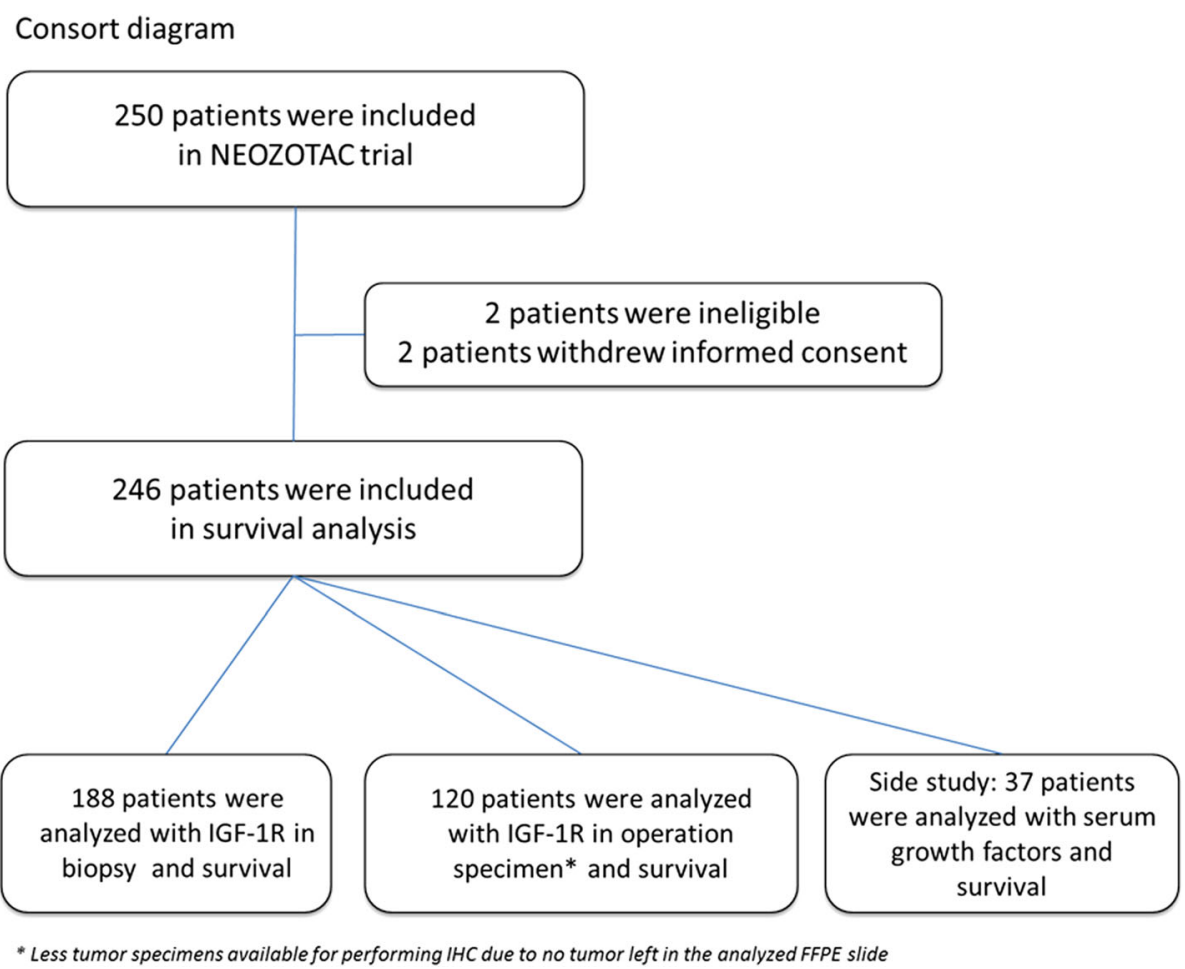

Fig. 1 Consort diagram of the trial

\section{Treatment}

Women received 6 cycles of neo-adjuvant TAC chemotherapy $\left(75 \mathrm{mg} / \mathrm{m}^{2}\right.$ of docetaxel, $50 \mathrm{mg} / \mathrm{m}^{2}$ of doxorubicin and $500 \mathrm{mg} / \mathrm{m}^{2}$ of cyclophosphamide) with or without ZA ( $4 \mathrm{mg}$ i.v. in $15 \mathrm{~min}$ within $24 \mathrm{~h}$ after chemotherapy, repeated every 21 days for 6 cycles). Pegfilgrastim (Neulasta $\left.{ }^{\circ}\right)$ was administered as primary prophylaxis $(6 \mathrm{mg}$ once per cycle) as a subcutaneous injection $24 \mathrm{~h}$ after chemotherapy for all cycles. ZA therapy was combined with daily supplements of $500 \mathrm{mg}$ calcium and $400 \mathrm{IU}$ vitamin D.

\section{Randomization}

Patients were randomized at the LUMC Datacenter of the Department of Surgery using Pocock's minimization technique, stratified by center, clinical T-classification, clinical N-classification, and estrogen receptor status. The ALEA randomization program was used.

\section{Immunohistochemistry}

Formalin-fixed paraffin-embedded (FFPE) tumor tissue samples of pre-chemotherapy biopsies and surgical specimens were collected for analysis of IGF-1R expression using immunohistochemistry (IHC) (Fig. 1). The staining method is described extensively elsewhere [25].

\section{Blood sampling and analysis}

Non-fasting blood samples were obtained directly before chemotherapy administration to measure glucose, insulin, and IGF-1 levels. Samples were collected and kept on ice directly after drawing. After centrifuging, the supernatant was stored at $-80^{\circ} \mathrm{C}$ and, at the end of the study, was sent to the Leiden University Medical Center (LUMC) for analysis. Serum glucose levels were determined by spectrophotometry (Modular P800, Roche Diagnostics, Almere, The Netherlands), and insulin levels were analyzed with the chemiluminescence immunoassay (CIA) (Immulite 2500, Siemens, The Hague, The Netherlands). Serum levels of IGF-1 (IDS-iSYS) were analyzed with Immunodiagnostic Systems (Frankfurt, Germany). The IGF-1 assay is traceable to the WHO IS 02/254.17.

\section{Endpoints}

The primary endpoint of the study was $\mathrm{PCR}$, and the results of $\mathrm{pCR}$ are described elsewhere [23]. PCR was defined as the absence of residual invasive cancer within the breast and lymph nodes according to the Miller and Payne (MP) classification [28]. Secondary endpoints were DFS, defined as the time from date of inclusion until the date of the earliest documented local or distant recurrence, contralateral breast cancer including DCIS, second primary invasive cancer, or death from any cause, and OS, defined as the time from inclusion until date of death from any cause. Additionally, we studied the association between insulin, glucose, IGF-1 levels, and IGF-1R expression with survival outcomes. 


\section{Statistical analysis}

Median follow-up was calculated by applying the reverse Kaplan-Meier methodology. Cox regression models were used to evaluate the effect of ZA and other risk factors on DFS and OS. Hazard ratios (HRs) and 95\% confidence intervals (95\% CIs) were estimated. Relevant risk factors described in the literature or found to have a $P$ value of less than 0.1 in univariate analyses were incorporated in the multivariate model. All tests were two-tailed. $P$ values of less than 0.05 were considered significant. All analyses were computed using SPSS software ${ }^{\mathrm{TM}} 23.0$ (IBM Corp., Armonk, NY, USA).

\section{Results}

\section{Patient characteristics}

The clinical characteristics of the patients included in the study are shown in Table 1 and were described previously [23]. None of these patient characteristics were significantly different between the two groups. Of the total cohort, $39.4 \%$ had a postmenopausal status at the start of the study.

\section{Response}

The primary endpoint pCR was achieved in $13.3 \%$ of the total cohort. This was not significantly different between the two arms $(P=0.980)$. As described previously, $\mathrm{pCR}$ was also not significantly different between the two arms in a subgroup analysis of postmenopausal women (14.0\% versus $8.7 \%$ ) [23]. The $\mathrm{pCR}$ and recurrence rates are shown in Table 2. Patients with pCR after neoadjuvant chemotherapy had a numerically longer period of DFS
Table 2 Short-term and long-term outcome

\begin{tabular}{|c|c|c|c|}
\hline Response & $\begin{array}{l}\text { TAC + ZA } \\
N=122(49.6 \%)\end{array}$ & $\begin{array}{l}\text { TAC } \\
N=124(50.4 \%)\end{array}$ & $P$ value \\
\hline \multicolumn{4}{|l|}{ pCR breast and LN } \\
\hline Yes & $16(13.3 \%)$ & $16(13.2 \%)$ & \\
\hline No & $104(86.7 \%)$ & $105(86.8 \%)$ & 0.980 \\
\hline \multicolumn{4}{|l|}{ Miller and Payne } \\
\hline 1 & 19 (15.8\%) & $18(14.8 \%)$ & \\
\hline 2 & 35 (29.2\%) & 31 (25.4\%) & \\
\hline 3 & $24(20.0 \%)$ & $25(20.5 \%)$ & \\
\hline 4 & $21(17.5 \%)$ & $25(20.5 \%)$ & \\
\hline 5 & $21(17.5 \%)$ & $23(18.9 \%)$ & 0.950 \\
\hline \multicolumn{4}{|l|}{ Recurrence } \\
\hline Total & $29(23.8 \%)$ & $20(16.1 \%)$ & 0.134 \\
\hline Local & $5(4.1 \%)$ & $5(4.0 \%)$ & 0.979 \\
\hline Regional & $7(5.7 \%)$ & $4(3.2 \%)$ & 0.341 \\
\hline Distant & $27(22.1 \%)$ & $17(13.7 \%)$ & 0.085 \\
\hline Second primary tumor & $5(4.1 \%)$ & $5(4.0 \%)$ & 0.979 \\
\hline \multicolumn{4}{|l|}{ Death } \\
\hline Yes & $23(18.9 \%)$ & $11(8.9 \%)$ & \\
\hline No & 99 (81.1\%) & $113(91.1 \%)$ & 0.023 \\
\hline \multicolumn{4}{|l|}{ Cause of death } \\
\hline Breast cancer & $22(95.7 \%)$ & $11(91.6 \%)$ & 0.630 \\
\hline Other & $1(4.3 \%)$ & $1(8.3 \%)$ & \\
\hline
\end{tabular}

TAC docetaxel, doxorubicin, and cyclophosphamide, ZA zoledronic acid, $p C R$ pathologic complete response, $L N$ lymph nodes, MP Miller and Payne the italicized data have a significance of $>0.05$

Table 1 Patient characteristics

\begin{tabular}{|c|c|c|c|c|}
\hline & $\begin{array}{l}\text { TAC + ZA } \\
N=122(49.6 \%)\end{array}$ & $\begin{array}{l}\text { TAC } \\
N=124(50.4 \%)\end{array}$ & $\begin{array}{l}\text { IGF-1R biopsy data available } \\
N=188(76.4 \%)\end{array}$ & $\begin{array}{l}\text { Serum data available } \\
N=37 \\
(15 \%)\end{array}$ \\
\hline Median age (range), Years & $48.0(29-67)$ & $49.0(34-70)$ & $49(29-70)$ & $49(34-65)$ \\
\hline Median BMI (range), kg/m² & $26.1(18.5-40.0)$ & $25.0(18.3-42.0)$ & $25.0(18.3-42.0)$ & $24.9(19.4-39.5)$ \\
\hline \multicolumn{5}{|l|}{ Menopausal status } \\
\hline Pre/peri & $72(59.0 \%)$ & $75(60.5 \%)$ & $110(58.5 \%)$ & $24(64.9 \%)$ \\
\hline Post & $50(41.0 \%)$ & 47 (37.9\%) & $76(40.4 \%)$ & $13(35.1 \%)$ \\
\hline \multicolumn{5}{|l|}{ T-classification } \\
\hline $\mathrm{T} 1 / \mathrm{T} 2$ & $73(59.8 \%)$ & $71(57.3 \%)$ & $108(57.4 \%)$ & $21(56.8 \%)$ \\
\hline $\mathrm{T} 3 / \mathrm{T} 4$ & $49(40.2 \%)$ & $53(42.7 \%)$ & $80(42.6 \%)$ & $16(43.2 \%)$ \\
\hline \multicolumn{5}{|l|}{ N-classification } \\
\hline No & $54(44.3 \%)$ & $56(45.2 \%)$ & 90 (47.9\%) & $22(59.5 \%)$ \\
\hline $\mathrm{N}+$ & $68(55.7 \%)$ & $68(54.8 \%)$ & $98(52.1 \%)$ & $15(40.5 \%)$ \\
\hline \multicolumn{5}{|l|}{ HR-status } \\
\hline ER+ and/or PR+ & $101(82.8 \%)$ & $104(83.9 \%)$ & $158(84.0 \%)$ & $33(89.2 \%)$ \\
\hline ER- and PR- & $21(17.2 \%)$ & $20(16.1 \%)$ & $30(16.0 \%)$ & $4(10.8 \%)$ \\
\hline
\end{tabular}

$T A C$ docetaxel, doxorubicin and cyclophosphamide, $Z A$ zoledronic acid, $B M I$ body mass index, HR hormone receptor, ER estrogen receptor, $P R$ progesterone receptor, $p C R$ pathologic complete response, $L N$ lymph nodes, MP Miller and Payne 
(HR 0.253, 95\% CI 0.061-1.041, $P=0.057$ ), but OS was not associated with pCR (HR 0.389, 95\% CI 0.093-1.624, $P=0.195)$ (Fig. 2a, b).

\section{Survival outcomes}

The median follow-up was 6.43 years (95\% CI 6.25-6.61). Kaplan-Meier curves of survival rates are shown in Fig. 2. Risk factors associated with survival as described in the literature and those with $P<0.1$ in univariate analyses were included in the regression model for multivariate analysis of mortality determinants. A Cox model was used to study the associations between risk factors and survival outcomes. The estimated HRs and associated 95\% confidence intervals for univariate and multivariate analyses for OS and DFS are shown in Tables 3 and 4, respectively. Age, hormone receptor status, $\mathrm{T}$ status, $\mathrm{N}$ status, and
A

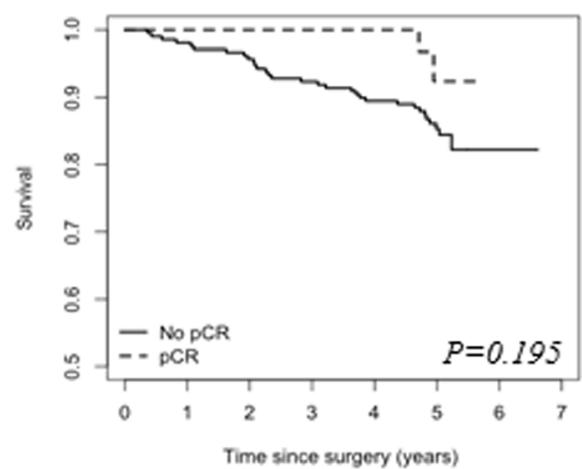

C

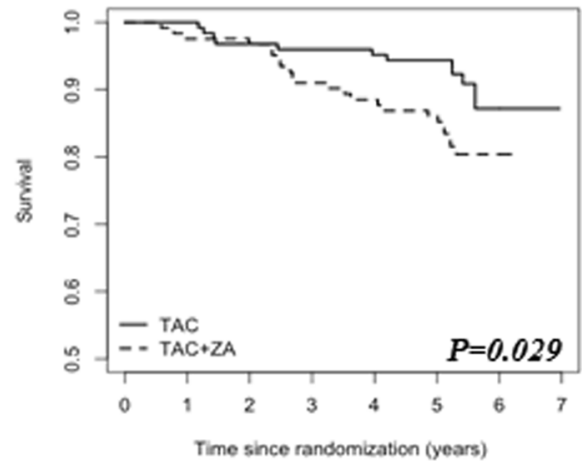

$\mathbf{E}$

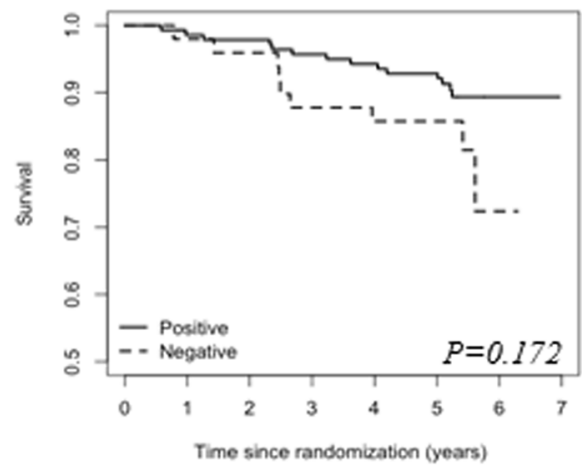

B

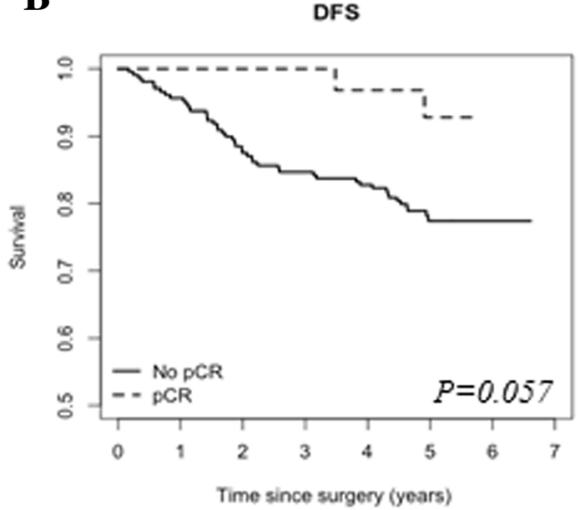

D

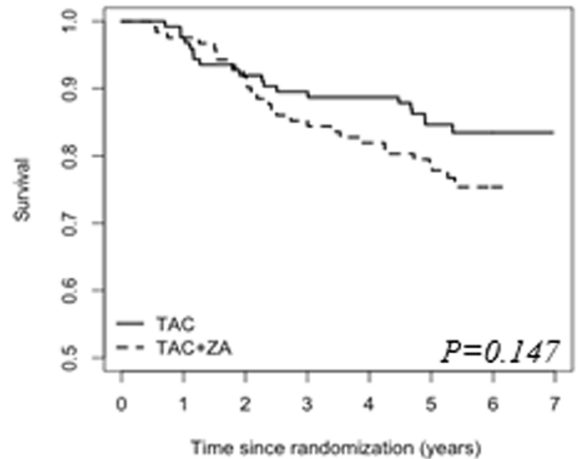

F

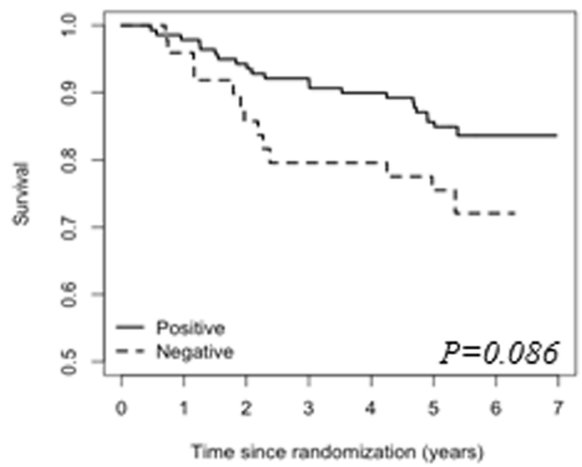

Fig. 2 Kaplan-Meier curves of overall survival (left column) and disease free-survival (right column) for pCR (a and $\mathbf{b}$ ), for treatment with or without zoledronic acid (c and $\mathbf{d}$ ), and IGF-1R expression before neoadjuvant chemotherapy (e and $\mathbf{f}$ ). Note: $P$-values are given for the univariate analyses of the Cox regression analyses. Bold values indicate that $P<0.05$. Abbreviations: IGF-1, insulin-like growth factor 1; DFS, disease-free survival; OS, overall survival, pCR, pathological complete response 
Table 3 Univariate and multivariate Cox models of OS

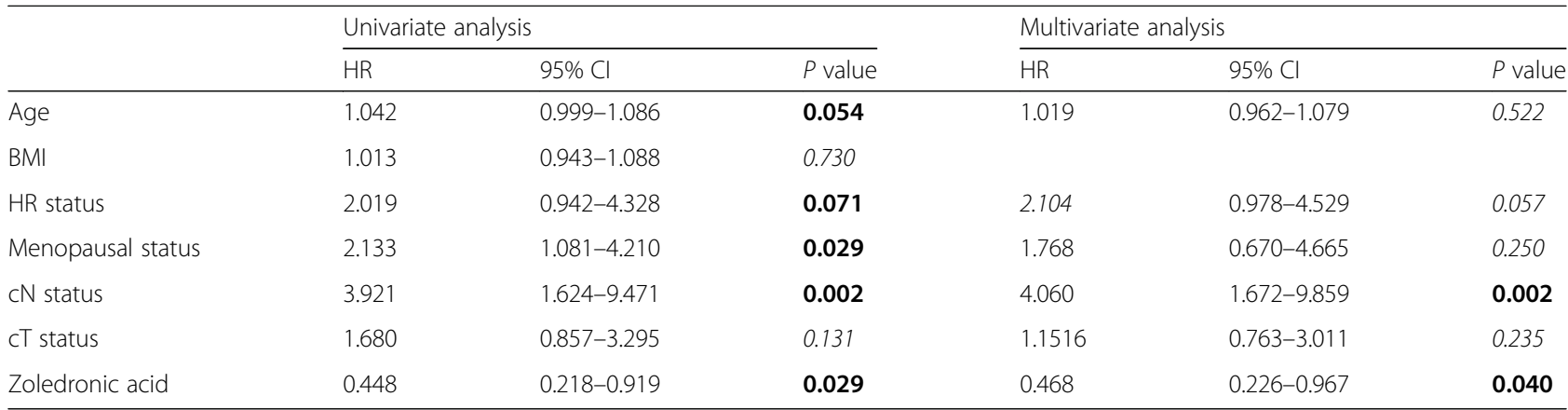

Bold values indicate that $P<0.05 O S$ overall survival, $H R$ hazard ratio, $C l$ confidence interval, $B M I$ body mass index

the italicized data have a significance of $>0.05$

menopausal status were adjusted for in the multivariate Cox model. Women who received ZA had a significantly worse OS than women who did not receive ZA in univariate analyses (HR 0.448, 95\% CI 0.218-0.919, $P=0.029$ ) (Fig. 2c) and in multivariate analyses (HR 0.468, 95\% CI $0.226-0.967, P=0.040$ ). DFS did not significantly differ between groups in univariate analysis (HR 0.656, 95\% CI $0.371-1.160, P=0.147$ ) (Fig. 2d). In the ZA arm, one patient died of stage IV lung cancer, and in the control arm, one patient died of unknown causes. The percentage of breast cancer deaths was not significantly different between both arms. In a subgroup analysis of postmenopausal women, the addition of ZA to chemotherapy did not affect DFS or OS (HR 0.539, 95\% CI $0.228-1.273, P=$ 0.159 ; HR 0.464, 95\% CI 0.176-1.222, $P=0.120$, respectively) (Fig. 3a, b). There was also no significant difference in survival (DFS or OS) between the two arms in the premenopausal subgroup (HR 0.798 , 95\% CI $0.369-1.725$, $P=0.565$; HR 0.456 , 95\% CI $0.156-1.336, P=0.152$, respectively) (Fig. 3c, d).

\section{IGF pathway analysis}

IGF-1R expression data was available for 188 patients before and 120 patients after chemotherapy treatment. The clinical characteristics of the patients included in the IGF pathway analysis are shown in Table 1 and were described previously [29]. The presence of IGF-1R expression in the tumor pre-treatment was numerically related to DFS, but this was not significant (HR 0.549, 95\% CI 0.276-1.089, $P=0.086$ ) (Fig. 2e), and it was not associated with OS (HR 0.562, 95\% CI 0.246-1.285, $P=$ 0.172) (Fig. 2f). In patients with HR-positive breast cancer, the presence of baseline IGF-1R tumor expression was associated with a better DFS in univariate analyses (HR 0.433, 95\% CI 0.198-0.946 $P=0.036$ ), but not in multivariate analysis (HR 0.484 , 95\% CI 0.214 $1.096, P=0.082)$. There was no significant association between the IGF-1R receptor and OS (HR 0.433, 95\% CI $0.198-0.946 P=0.120$ ). Neither the presence of IGF-1R expression after neoadjuvant chemotherapy nor the decrease in expression during therapy was related to survival. Furthermore, treatment with ZA had no influence on the IGF-1R expression in the surgical specimen after chemotherapy treatment.

In a subgroup of patients $(N=37)$, baseline serum levels of glucose, insulin, and IGF-1 were measured. Patient characteristics are reported in Table 1 . These were not significantly different compared to the total cohort. Lower serum insulin levels were associated with improved DFS (HR 1.025, 95\% CI 1.005-1.045, $P=0.014$ ), but not OS

Table 4 Univariate and multivariate Cox models of DFS

\begin{tabular}{|c|c|c|c|c|c|c|}
\hline & \multicolumn{3}{|c|}{ Univariate analysis } & \multicolumn{3}{|c|}{ Multivariate analysis } \\
\hline & $H R$ & $95 \% \mathrm{Cl}$ & $P$ value & $H R$ & $95 \% \mathrm{Cl}$ & $P$ value \\
\hline Age & 1.034 & $0.998-1.070$ & 0.061 & 1.036 & $0.850-2.637$ & 0.043 \\
\hline BMl & 0.989 & $0.930-1.053$ & 0.739 & & & \\
\hline HR status & 1.698 & $0.868-3.323$ & 0.122 & 1.799 & $0.916-3.536$ & 0.088 \\
\hline Menopausal status & 1.393 & $0.795-2.442$ & 0.247 & & & \\
\hline cN status & 2.724 & $1.420-5.224$ & 0.003 & 2.811 & $1.461-5.407$ & 0.002 \\
\hline cT status & 1.569 & $0.896-2.748$ & 0.115 & 1.497 & $0.850-2.637$ & 0.162 \\
\hline Zoledronic acid & 0.656 & $0.371-1.160$ & 0.147 & & & \\
\hline
\end{tabular}

Bold values indicate that $P<0.05$

$D F S$ disease-free survival, $H R$ hazard ratio, $C l$ confidence interval, $B M I$ body mass index

the italicized data have a significance of $>0.05$ 
A

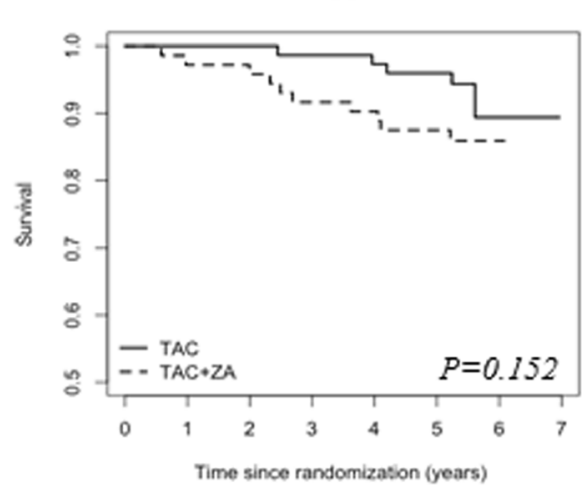

C

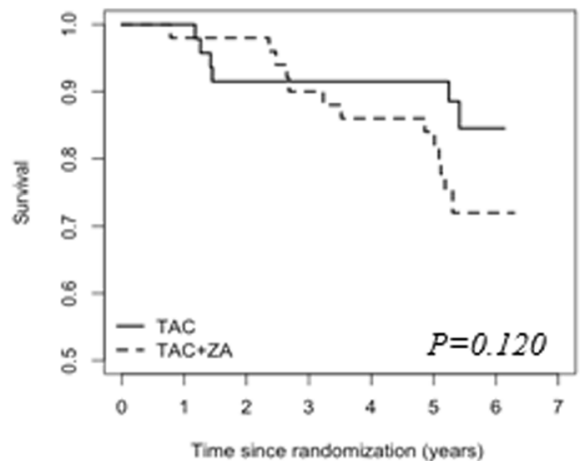

B

DFS

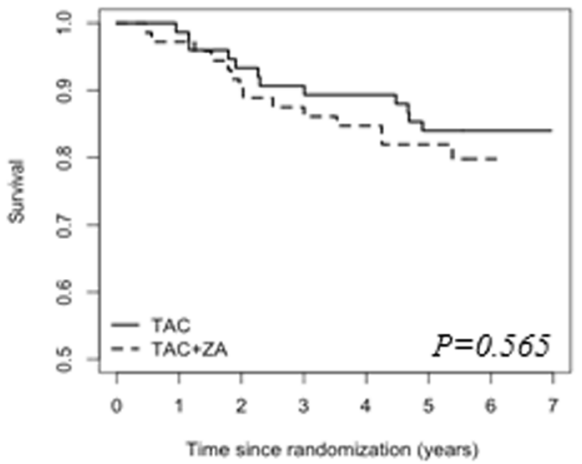

D

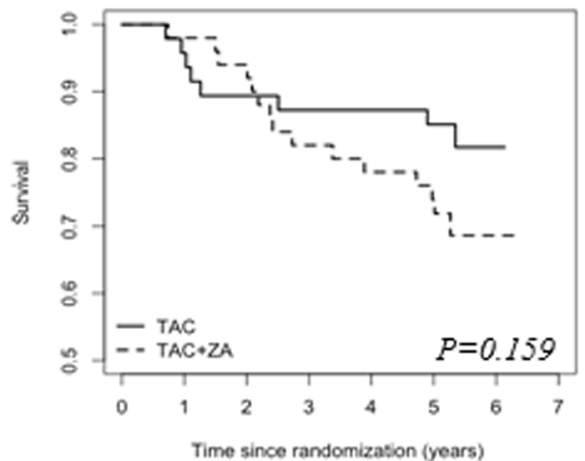

Fig. 3 Kaplan-Meier curves of overall survival (left column) and disease-free survival (right column) for pre/perimenopausal women (a, b) and postmenopausal women $(\mathbf{c}, \mathbf{d}) . P$ values are given for the univariate analyses of the Cox regression analyses. DFS, disease-free survival; OS, overall survival

(HR 1.073 95\% CI 0.953-1.209, $P=0.244$ ). Glucose and IGF-1 concentrations were not associated with survival.

\section{Discussion}

This study found that ZA as an adjunct to neoadjuvant chemotherapy had no beneficial effect in patients with stage II/III HER2-negative breast cancer receiving TAC chemotherapy and, in pre- and postmenopausal patients, was associated with worse OS, but not DFS. Additionally, in a post hoc analysis, there was no beneficial effect of ZA in postmenopausal patients. Interestingly, lower insulin levels were associated with improved DFS, but not with OS.

The negative impact of ZA on OS when used as an adjunct to neoadjuvant chemotherapy was not expected, as several studies have shown a benefit of ZA in the adjuvant setting in postmenopausal women [4]. Our study population may explain the negative impact of ZA on survival, as the majority (59.8\%) of patients were premenopausal. Accordingly, the Azure trial showed that ZA in the adjuvant setting was associated with worse DFS and OS in a subgroup of patients younger than 40 years old, who are presumably largely premenopausal.
[30]. However, we also did not find a benefit in postmenopausal patients.

Moreover, a major difference between adjuvant and neo-adjuvant use of BPs is the length of administration. Neoadjuvant BPs are administered for a shorter time period and therefore may not positively impact survival outcomes. In the JONIE1 trial, ZA did not have a beneficial effect on survival in the neoadjuvant setting [31], although the authors did find a positive association with pCR in previous studies [32]. In keeping with our results, a meta-analysis of four studies did not show any effect of ZA addition to neoadjuvant chemotherapy on pCR rate [16].

In a predefined additional exploratory side study, lower serum insulin levels were associated with improved DFS. In keeping with this result, patients with insulin levels greater than $13 \mu \mathrm{IU} / \mathrm{mL}$ had a twofold increased risk for disease progression compared to patients with insulin levels below this cut-off [33]. Goodwin et al. found that higher fasting insulin levels at baseline in breast cancer patients without diabetes were also associated with worse OS [34]. Higher insulin levels may give the tumor a growth advantage, as most breast tumors express the IGF- 
1R and IR-A, both of which are involved in proliferation and tumorigenesis and are associated with tumor progression $[27,35]$.

Our study has some limitations. We are aware that the sample size is small and the results should therefore be interpreted with caution. The majority of the patients included in this study were premenopausal women, but the positive effect of ZA on survival would be expected in postmenopausal women. Our post hoc analyses of postmenopausal women are not statistically powered, making it impossible to draw firm conclusions. Patients using BPs at baseline were excluded; however, the use of adjuvant BPs might have influenced the survival outcome, but this information is not available in our study. The sample size of the additional exploratory study of growth factors was small. However, the results of our study provide further evidence of the importance of the insulin and IGF-1R pathway in breast cancer.

\section{Conclusion}

Our study does not support the use of ZA as an adjunct to neoadjuvant chemotherapy in patients with breast cancer.

\section{Acknowledgements \\ We thank the BOOG and all the participating centers, especially because of the shorter accrual time than expected. We are greatly indebted to the patients for participating in this study. We thank the LUMC Datacenter, Department of Surgery, especially Linda Verhoeff, for trial coordination and data collection. The authors gratefully acknowledge S. Hendrickson for her help with English language editing.}

\section{Authors' contributions}

All the authors contributed for the preparation of this manuscript. JK, $H L, J N$, GL, EM, and JN initiated and designed the study. AC, SV, VS, EM, JH, LW, LK, $M D, M P, H L$, and BV participated in the data acquisition and coordination of the study. HP and MF gave advice on the statistical analysis and wrote the statistical section of the manuscript. SG performed the statistical analysis, wrote the manuscript, and was responsible for the editing and preparation of the manuscript for submission. HP, JH, and JK critically revised the manuscript. All authors read and approved the final article.

\section{Funding}

This work was supported by grants from the Dutch Cancer Society [20104682], Amgen, Novartis and Sanofi Aventis.

\section{Availability of data and materials}

Not applicable.

\section{Ethics approval and consent to participate}

The study (NCT01099436) was conducted in accordance with the Declaration of Helsinki (October 2008) and was approved by the Ethics Committee of the LUMC in agreement with the Dutch law for medical research involving human subjects.

\section{Consent for publication}

Not applicable.

\section{Competing interests}

The authors declare that they have no competing interests.

\section{Author details}

${ }^{1}$ Department of Medical Oncology, Leiden University Medical Center, Albinusdreef 2, Leiden, P.O. Box 9600, 2300 RC Leiden, The Netherlands.
${ }^{2}$ Department of Endocrinology, Leiden University Medical Center, Leiden, The Netherlands. ${ }^{3}$ Department of Radiotherapy, University Medical Center Utrecht, Utrecht, The Netherlands. ${ }^{4}$ Department of Pathology, Leiden University Medical Center, Leiden, The Netherlands. ${ }^{5}$ Department of Surgery, Leiden University Medical Center, Leiden, The Netherlands. ${ }^{6}$ Department of Medical Oncology, Amphia hospital, Breda, The Netherlands. ${ }^{7}$ Department of Clinical Oncology, Catharina Ziekenhuis, Eindhoven, The Netherlands. ${ }^{8}$ Department of Medical Oncology, Deventer hospital, Deventer, The Netherlands. ${ }^{9}$ Department of Clinical Oncology, Maxima Medisch Centrum, Veldhoven, The Netherlands. ${ }^{10}$ Department of Clinical Oncology, Elkerliek Ziekenhuis, Helmond, The Netherlands. " ${ }^{11}$ Department of Medical Oncology, Cancer Center Amsterdam, Amsterdam Medical Centers, University of Amsterdam, Amsterdam, The Netherlands. ${ }^{12}$ Department of Medical Statistics and Bioinformatics, Leiden University Medical Center, Leiden, The Netherlands. ${ }^{13}$ Mathematical Department, Leiden University, Leiden, The Netherlands. ${ }^{14}$ Department of Clinical Oncology, Radboud University, Nijmegen, The Netherlands. ${ }^{15}$ Dutch Breast Cancer Research Group (BOOG), Amsterdam, The Netherlands.

Received: 25 April 2019 Accepted: 31 July 2019

Published online: 28 August 2019

\section{References}

1. Charehbili A, Fontein DB, Kroep JR, et al. Can zoledronic acid be beneficial for promoting tumor response in breast cancer patients treated with neoadjuvant chemotherapy? J Clin Med. 2013;2:188-200.

2. Drake MT, Clarke BL, Khosla S. Bisphosphonates: mechanism of action and role in clinical practice. Mayo Clin Proc. 2008;83:1032-45.

3. Coleman R, Body JJ, Aapro M, et al. Bone health in cancer patients: ESMO Clinical Practice Guidelines. Ann Oncol. 2014;25(Suppl 3):iii124-37.

4. Early Breast Cancer Trialists' Collaborative G. Adjuvant bisphosphonate treatment in early breast cancer: meta-analyses of individual patient data from randomised trials. Lancet. 2015;386:1353-61.

5. Ottewell PD, Wang N, Brown HK, et al. Zoledronic acid has differential antitumor activity in the pre- and postmenopausal bone microenvironment in vivo. Clin Cancer Res. 2014;20:2922-32.

6. Hadji P, Coleman RE, Wilson C, et al. Adjuvant bisphosphonates in early breast cancer: consensus guidance for clinical practice from a European panel. Ann Oncol. 2016;27:379-90.

7. Strobl S, Wimmer K, Exner R, et al. Adjuvant bisphosphonate therapy in postmenopausal breast cancer. Curr Treat Options in Oncol. 2018;19:18.

8. van der Pluijm G, Que I, Sijmons B, et al. Interference with the microenvironmental support impairs the de novo formation of bone metastases in vivo. Cancer Res. 2005:65:7682-90.

9. Winter MC, Holen I, Coleman RE. Exploring the anti-tumour activity of bisphosphonates in early breast cancer. Cancer Treat Rev. 2008;34:453-75.

10. Tang X, Zhang Q, Shi S, et al. Bisphosphonates suppress insulin-like growth factor 1-induced angiogenesis via the HIF-1alpha/NEGF signaling pathways in human breast cancer cells. Int J Cancer. 2010;126:90-103.

11. Fromigue $\mathrm{O}$, Kheddoumi N, Body JJ. Bisphosphonates antagonise bone growth factors' effects on human breast cancer cells survival. Br J Cancer. 2003:89:178-84.

12. Wang $Y$, Nishida S, Elalieh $\mathrm{HZ}$, et al. Role of IGF-I signaling in regulating osteoclastogenesis. J Bone Miner Res. 2006;21:1350-8.

13. Santini D, Martini F, Fratto ME, et al. In vivo effects of zoledronic acid on peripheral gammadelta T lymphocytes in early breast cancer patients. Cancer Immunol Immunother. 2009;58:31-8.

14. Kunzmann V, Bauer E, Feurle J, et al. Stimulation of gammadelta T cells by aminobisphosphonates and induction of antiplasma cell activity in multiple myeloma. Blood. 2000;96:384-92.

15. Rogers $\mathrm{TL}$, Holen I. Tumour macrophages as potential targets of bisphosphonates. J Transl Med. 2011;9:177.

16. Kroep JR, Charehbili A, Coleman RE, et al. Effects of neoadjuvant chemotherapy with or without zoledronic acid on pathological response: a meta-analysis of randomised trials. Eur J Cancer. 2016;54:57-63.

17. Misso G, Porru M, Stoppacciaro A, et al. Evaluation of the in vitro and in vivo antiangiogenic effects of denosumab and zoledronic acid. Cancer Biol Ther. 2012;13:1491-500.

18. Santini D, Vincenzi B, Dicuonzo G, et al. Zoledronic acid induces significant and long-lasting modifications of circulating angiogenic factors in cancer patients. Clin Cancer Res. 2003;9:2893-7. 
19. Rack B, Juckstock J, Genss EM, et al. Effect of zoledronate on persisting isolated tumour cells in patients with early breast cancer. Anticancer Res. 2010;30:1807-13.

20. Aft R, Naughton M, Trinkaus $K$, et al. Effect of zoledronic acid on disseminated tumour cells in women with locally advanced breast cancer: an open label, randomised, phase 2 trial. Lancet Oncol. 2010;11:421-8.

21. Ottewell PD, Monkkonen $\mathrm{H}$, Jones $\mathrm{M}$, et al. Antitumor effects of doxorubicin followed by zoledronic acid in a mouse model of breast cancer. J Natl Cancer Inst. 2008;100:1167-78.

22. Coleman RE, Winter MC, Cameron D, et al. The effects of adding zoledronic acid to neoadjuvant chemotherapy on tumour response: exploratory evidence for direct anti-tumour activity in breast cancer. Br J Cancer. 2010; 102:1099-105.

23. Charehbili A, van de Ven S, Smit VT, et al. Addition of zoledronic acid to neoadjuvant chemotherapy does not enhance tumor response in patients with HER2-negative stage II/III breast cancer: the NEOZOTAC trial (BOOG 2010-01). Ann Oncol. 2014;25:998-1004.

24. Lelievre L, Clezardin P, Magaud L, et al. Comparative study of neoadjuvant chemotherapy with and without Zometa for management of locally advanced breast cancer with serum VEGF as primary endpoint: the NEOZOL Study. Clin Breast Cancer. 2018;18(6):e1311-21.

25. de Groot S, Vreeswijk MP, Welters MJ, Gravesteijn G, Boei JJ, Jochems A Houtsma D, Putter H, van der Hoeven JJ, Nortier JW, Pijl H, Kroep JR. The effects of short-term fasting on tolerance to (neo) adjuvant chemotherapy in HER2-negative breast cancer patients: a randomized pilot study. BMC Cancer. 2015:15:652.

26. Huang J, Morehouse C, Streicher K, et al. Altered expression of insulin receptor isoforms in breast cancer. PLoS One. 2011;6:e26177.

27. Djiogue S, Nwabo Kamdje AH, Vecchio L, et al. Insulin resistance and cancer: the role of insulin and IGFs. Endocr Relat Cancer. 2013;20:R1-R17.

28. Ogston KN, Miller ID, Payne S, et al. A new histological grading system to assess response of breast cancers to primary chemotherapy: prognostic significance and survival. Breast. 2003;12:320-7.

29. de Groot S, Charehbili A, van Laarhoven HW, et al. Insulin-like growth factor 1 receptor expression and IGF1R 3129G > T polymorphism are associated with response to neoadjuvant chemotherapy in breast cancer patients: results from the NEOZOTAC trial (BOOG 2010-01). Breast Cancer Res. 2016:18:3.

30. Coleman RE, Collinson M, Gregory W, et al. Benefits and risks of adjuvant treatment with zoledronic acid in stage I//II breast cancer. 10 years followup of the AZURE randomized clinical trial (BIG 01/04). J Bone Oncol. 2018; 13:123-35.

31. Ishikawa T, Akazawa K, Hasegawa Y, et al. Survival outcomes of neoadjuvant chemotherapy with zoledronic acid for HER2-negative breast cancer. J Surg Res. 2017:220:46-51

32. Hasegawa Y, Tanino H, Horiguchi J, et al. Randomized controlled trial of zoledronic acid plus chemotherapy versus chemotherapy alone as neoadjuvant treatment of HER2-negative primary breast cancer (JONIE Study). PLoS One. 2015:10:e0143643.

33. Ferroni $\mathrm{P}$, Riondino $\mathrm{S}$, Laudisi $\mathrm{A}$, et al. Pretreatment insulin levels as a prognostic factor for breast cancer progression. Oncologist. 2016;21:1041-9.

34. Goodwin PJ, Ennis M, Pritchard Kl, et al. Fasting insulin and outcome in early-stage breast cancer: results of a prospective cohort study. J Clin Oncol. 2002;20:42-51

35. Ryu TY, Park J, Scherer PE. Hyperglycemia as a risk factor for cancer progression. Diabetes Metab J. 2014;38:330-6.

\section{Publisher's Note}

Springer Nature remains neutral with regard to jurisdictional claims in published maps and institutional affiliations.

Ready to submit your research? Choose BMC and benefit from:
- fast, convenient online submission
- thorough peer review by experienced researchers in your field
- rapid publication on acceptance
- support for research data, including large and complex data types
- gold Open Access which fosters wider collaboration and increased citations
- maximum visibility for your research: over 100M website views per year
At BMC, research is always in progress.
Learn more biomedcentral.com/submissions

